\title{
Tempo de armazenamento e temperatura na porcentagem e velocidade de germinação das sementes de camomila
}

\author{
Packing time and temperature on the percentage and germination \\ speed of chamomile seeds \\ José Roberto Pinto de Souza ${ }^{\mathrm{I}}$ Lúcia Sadayo Assari Takahashi ${ }^{\mathrm{I}}$ \\ Andréia Emiko Yoshida ${ }^{\text {II }}$ Marília Cherobim Guiraud ${ }^{I I}$ \\ Juliana Navarro Rocha ${ }^{\text {III }}$
}

\section{RESUMO}

A camomila é uma planta herbácea e anual. Suas flores são usadas na medicina popular como droga vegetal $e$ também como aromatizante. Realizaram-se dois experimentos com o objetivo de avaliar o tempo de armazenamento e a temperatura na porcentagem e velocidade de germinação das sementes de camomila. O primeiro experimento utilizou sementes de camomilas produzidas no Horto Medicinal da Universidade Estadual de Londrina, PR. Elas foram beneficiadas, acondicionadas em sacos de papel e armazenadas em câmara fria por um, dois, três e quatro anos. O teste de germinação foi realizado em temperatura alternada $15-25^{\circ} \mathrm{C}$ e fotoperíodo de 8 horas. Avaliou-se a porcentagem e o índice de velocidade de germinação (IVG), em oito repetições de 100 sementes cada uma. As sementes de camomila utilizadas no segundo experimento foram comerciais. Os tratamentos foram: temperaturas constantes de $10^{\circ} \mathrm{C}$ e $15^{\circ} \mathrm{C}$ e temperaturas alternadas de $10-15^{\circ} \mathrm{C}$ e $10-20^{\circ} \mathrm{C}$, com fotoperíodo de 12 horas. As avaliações foram realizadas no sétimo e no décimo quarto dia após a semeadura (DAS). O potencial de germinação e o índice de velocidade de germinação das sementes foram mantidos nos dois primeiros anos de armazenamento. A germinação das sementes foi reduzida para $3,3 \%$ com a temperatura de $10^{\circ} \mathrm{C}$ ao sétimo DAS. As temperaturas constantes de $10^{\circ} \mathrm{C}$ e $15^{\circ} \mathrm{C}$ e alternadas de $10-15^{\circ} \mathrm{C}$ e $10-20^{\circ} \mathrm{C}$ proporcionaram germinação das sementes superior a $80 \%$ ao final do décimo quarto DAS.

Palavras-chave: Chamomilla recutita (L.) Rauschert, conservação, longevidade, qualidade fisiológica.

\section{ABSTRACT}

Chamomile is an annual herbaceous species. Its flowers are used in popular medicine and as a vegetable flavour.
It propagates for seeds. The objective of these trials was to evaluate the ideal temperature, packing time on the percentage and germination speed of chamomile. The first trial used seeds from a medicinal vegetable garden from Universidade Estadual de Londrina, Paraná, Brazil. They were treated, packed in paper bags and kept in refrigerate chamber during one, two, three and four years. In germination test it was used $25^{\circ} \mathrm{C}$ with 10 hours of light and 14 hours of dark. It was evaluated the percentage and germination speed index (GSI) in 8 replicates with 100 seeds each one. The seeds used in the second trial were commercial ones. The tested treatments were: constant temperatures of $10^{\circ} \mathrm{C}$ and $15^{\circ} \mathrm{C}$ with 12 hours of photoperiod, and alternated temperatures of $10^{\circ} \mathrm{C} / 15^{\circ} \mathrm{C}$ and $10^{\circ} \mathrm{C} / 20^{\circ} \mathrm{C}$ with 10 hours of photoperiod. The evaluations were made at 7 th and 14th days after seeding. The seeds packed until 2 years showed greatest percentage and germination speed index. The temperature of $10^{\circ} \mathrm{C}$ reduced the germination for $3.3 \%$ at 7 DAS. The constant temperature of $10^{\circ} \mathrm{C}$ and $15^{\circ} \mathrm{C}$, and alternated in $10^{\circ} \mathrm{C} / 15^{\circ} \mathrm{C}$ and $10^{\circ} \mathrm{C} / 20^{\circ} \mathrm{C}$ provided germination of the seeds superior to $80 \%$ in the end of 14 th day.

Key words: Chamomilla recutita (L.) Rauschert, conservation, longevity, physiology quality.

\section{INTRODUÇÃO}

A camomila [Chamomilla recutita (L.) Rauschert] é uma planta herbácea, anual e aromática, originária do sul e leste da Europa, bem como do oeste asiático. Suas flores são reunidas em capítulos com flores centrais amarelas e as marginais de corola ligulada e tubulosa branca. É usada na medicina popular como calmante, antiinflamatória, analgésica, antiespamódica,

IDepartamento de Agronomia, Centro de Ciências Agrárias (CCA), Universidade Estadual de Londrina (UEL), 86051-990, CP 6001, Londrina, PR, Brasil. E-mail: jose@uel.br. Autor para correspondência.

${ }^{\text {II } C u r s o ~ d e ~ A g r o n o m i a, ~ C C A, ~ U E L, ~ L o n d r i n a, ~ P R, ~ B r a s i l . ~}$

IIIPrograma de pós-graduação em Agronomia, CCA, UEL, Londrina, PR, Brasil. 
carminativa, cicatrizante, emenagoga, clareadora de cabelos e também como aromatizante (LORENZI \& MATOS, 2002). A parte utilizada para fins tanto aromáticos quanto medicinais é o capítulo floral (NÓBREGA et al., 1995).

O Estado do Paraná é o maior produtor nacional de camomila (491t na safra de 2002), com crescimento significativo nos últimos sete anos. $\mathrm{O}$ alto custo da produção e os problemas tecnológicos de mercado causaram a diminuição da produção, na safra corrente. O que se procura é a melhoria na qualidade do produto final e também do processo produtivo, e isso pode ser feito através da obtenção de sementes de melhor qualidade (AGRO-FAUNA, 2003).

A semente contém todas as potencialidades produtivas da planta, sendo esta a razão de ser considerada um dos insumos mais importantes para a agricultura (POPINIGIS, 1985). As sementes de camomila são frutos do tipo aquênio que, sem beneficiamento, apresentam número elevado de sementes chochas e impurezas, o que reduz muito a qualidade, originando baixa germinação e estandes irregulares (CORREA JÚNIOR \& TANIGUCHI, 1992; NÓBREGA et al., 1995).

Para se obter boa produção, a lavoura deve apresentar população adequada de plantas. Além dos cuidados na operação de semeadura, a produção da cultura depende do uso de sementes de boa qualidade física, fisiológica e sanitária (PIZZINATTO et al., 1991). Os fatores que afetam a germinação das sementes são: genótipo das plantas, condições climáticas predominantes durante a maturação, grau de injúrias mecânicas, condições ambientais de armazenamento, sementes atacadas por microrganismos e insetos, densidade e tamanho das sementes, idade das sementes, disponibilidade de água e temperatura durante a embebição (CARVALHO \& NAKAGAWA, 2000).

As sementes de várias espécies nãotropicais podem ter dormências superadas quando hidratadas ou expostas às baixas temperaturas (ZAIDAN \& BARBEDO, 2004). A importância do conhecimento das condições ótimas de temperatura, luz, substrato e umidade para a germinação das sementes são fundamentais. Algumas espécies de plantas germinam melhor em temperaturas mais baixas, outras em temperaturas mais altas, mas é no limite da temperatura ótima que a germinação se processa mais rapidamente.

A análise realizada com sementes de camomila beneficiadas demonstrou que a germinação das sementes sobre papel na caixa plástica "gerbox" foi favorecida pela temperatura constante de $15^{\circ} \mathrm{C}$ (NÓBREGA et al., 1995). As Regras para Análise de Sementes (BRASIL, 1992) propõem que os testes de germinação em laboratório para sementes de camomila sejam feitos sobre papel, com faixas de temperatura de $20-30^{\circ} \mathrm{C}$ ou $20^{\circ} \mathrm{C}$ constante, com ou sem luz e o uso de pré-esfriamento das sementes. No entanto, AGUILERA et al. (1998) concluíram que a temperatura ideal para a germinação de sementes de camomila deveria ser constante, igual ou inferior a $20^{\circ} \mathrm{C}$.

A qualidade das sementes é determinada por fatores genéticos, físicos, fisiológicos e sanitários, e o conhecimento sobre sua formação e fisiologia é de fundamental importância (TOLEDO \& MARCOS FILHO, 1977).

$\mathrm{Na}$ maioria das culturas propagadas por sementes, a época de colheita não coincide com a época mais adequada para a semeadura; por isso, a importância do armazenamento das sementes (TOLEDO \& MARCOS FILHO, 1977). A importância da conservação está na função básica de manter sua qualidade fisiológica, já que o armazenamento adequado diminui a possibilidade e a velocidade de deterioração, um processo prejudicial e irreversível (DELOUCHE et al., 1973).

Conhecer o comportamento das sementes diante de diferentes condições de armazenamento (temperatura, umidade relativa do ar e embalagem utilizada) é importante para o manejo da espécie durante este período (ARAÚJO et al., 1994; PIÑA-RODRIGUEZ \& JESUS, 1992). O armazenamento em ambientes de baixa umidade relativa do ar, com baixas temperaturas, favorece a conservação das sementes ortodoxas por períodos maiores (CARVALHO \& NAKAGAWA, 2000).

Para obter uma previsão do potencial de armazenamento das sementes, é necessário definir quais os testes de qualidade refletem melhor o histórico daquelas sementes, incluindo a formação da semente, a maturação, a colheita, o acondicionamento e a secagem (STUMPF et al., 1996). TOMPSETT (1992) encontrou que as sementes menores, como é o caso de camomila, são secadas mais rapidamente e, devido a isso, perdem a viabilidade com maior freqüência do que sementes maiores.

A partir dessas constatações, e considerando que a camomila é uma planta originada de regiões de clima temperado, este trabalho avaliou a qualidade das sementes após diferentes períodos de armazenamento em câmara fria e o efeito de temperaturas na velocidade e porcentagem de germinação.

Ciência Rural, v.37, n.4, jul-ago, 2007. 


\section{MATERIAL E MÉTODOS}

Foram realizados dois experimentos, um para avaliar a qualidade das sementes de camomila armazenadas em câmara fria de 1999 a 2002, e um outro para avaliar a germinação das sementes submetidas a diferentes temperaturas.

\section{Primeiro experimento}

O experimento foi conduzido no Laboratório de Fitotecnia da Universidade Estadual de Londrina (UEL). Foram utilizadas sementes de camomila produzidas e coletadas no Horto Medicinal do Departamento de Agronomia, UEL, nos anos de 1999, 2000, 2001 e 2002. A secagem dos capítulos florais foi realizada em estufa com circulação de ar forçado a $32^{\circ} \mathrm{C}$ até atingir umidade de $12 \%$. Em seguida, elas foram beneficiadas com a utilização de peneiras e soprador, acondicionadas em sacos de papel e armazenadas em câmara fria à temperatura de $10^{\circ} \mathrm{C}$. Foi realizado um teste de germinação das sementes de camomila logo após a operação de beneficiamento que detectou uma porcentagem de germinação média de 50,2\%. As sementes ficaram armazenadas pelo período de um, dois, três e quatro anos e, depois de decorridos estes períodos, foram avaliados os potenciais de germinação.

O teste de germinação foi realizado com as sementes granadas e separadas através da utilização da técnica desenvolvida por SOUZA et al. (2000). As sementes selecionadas foram colocadas para germinar sobre papel em caixas plásticas (uma parcela experimental), desinfetadas com solução de Hipoclorito de Sódio (2\%) e colocadas na câmara de germinação, tipo BOD, com temperatura de $15-25^{\circ} \mathrm{C}$ e fotoperíodo de oito horas (TAKAHASHI et al., 2001). A verificação da germinação das sementes foi realizada diariamente durante 14 dias. Considerou-se como início da germinação quando as plântulas apresentavam os dois primórdios foliares e uma radícula desenvolvida conforme a descrição das Regras para Análise de Sementes (BRASIL, 1992). E o índice de velocidade de germinação (IVG) foi avaliado segundo a metodologia sugerida por KRZYZANOWSKI et al. (1999).

O delineamento experimental utilizado foi o inteiramente casualizado, com quatro tratamentos com oito repetições de 100 sementes cada uma (800 sementes por tratamento). Os dados de porcentagem foram transformados para arco seno da Raiz X/100 e submetidos à análise de variância, sendo as médias comparadas pelo teste de Tukey a 5\% de probabilidade de erro.

\section{Segundo experimento}

O experimento foi conduzido no laboratório durante os meses de Julho de 2003 e Março de 2004.
As sementes de camomila utilizadas foram adquiridas no comércio e apresentavam 99,8\% de pureza. Elas estavam acondicionadas em sacos de papel e permaneceram armazenadas em câmara fria $\left(10^{\circ} \mathrm{C}\right)$ até $o$ início do experimento.

O delineamento experimental utilizado foi o de blocos inteiramente casualizados com arranjo fatorial 4x2 (quatro temperaturas e duas épocas de avaliação), com seis repetições de 100 sementes cada um. Os tratamentos testados foram: temperaturas alternadas $\left(10^{\circ} \mathrm{C}\right.$ na ausência de luz e $15^{\circ} \mathrm{C}$ na presença de luz; $10^{\circ} \mathrm{C}$ na ausência de luz e $20^{\circ} \mathrm{C}$ na presença de luz) e temperaturas constantes $\left(10^{\circ} \mathrm{C}\right.$ e $\left.15^{\circ} \mathrm{C}\right) . \mathrm{O}$ fotoperíodo utilizado foi de doze horas para todos os tratamentos. As avaliações dos testes de germinação foram realizadas no sétimo e no décimo quarto dia após a semeadura, conforme indicado nas Regras para Análise de Sementes (BRASIL, 1992). Foram consideradas como plântulas normais aquelas que apresentavam dois primórdios foliares e radículas desenvolvidas.

As sementes foram semeadas em caixas plásticas "gerbox" sobre papel de germinação sem qualquer tratamento. As caixas foram previamente desinfetadas com solução de hipoclorito de sódio a 2\% e acondicionadas na câmara de germinação tipo BOD.

Os dados obtidos foram submetidos à análise de variância e a comparação entre as médias foi realizada pelo teste de Tukey em nível de 5\% de probabilidade de erro.

\section{RESULTADOSE DISCUSSÃO}

Primeiro experimento

Nos resultados obtidos, foi possível verificar que a maior porcentagem de germinação ocorreu com as sementes de camomila armazenadas por, no máximo, dois anos, com média de $47 \%$. A partir do terceiro ano de armazenamento, essa porcentagem foi significativamente reduzida (Tabela 1). STUMPF et al. (1996) apresentaram resultados semelhantes ao trabalhar com sementes de cebola, com porcentagem de germinação diminuída a partir do segundo ano de armazenamento, em condições ambientais. Porém, trabalhos com forrageiras, capim-guiné (Panicum maximum) e braquiária (Brachiaria decumbens) mostraram que elas apresentaram um acréscimo na porcentagem de germinação quando armazenadas (GROB, 1968).

Em relação ao índice de velocidade de germinação, as sementes armazenadas por dois anos apresentaram maior índice, com redução com o aumento 
Tempo de armazenamento e temperatura na porcentagem e velocidade de germinação das sementes de camomila.

Tabela 1 - Porcentagem e velocidade de germinação de sementes de camomila armazenadas por diferentes períodos. Londrina, PR. 2004.

\begin{tabular}{lcc}
\hline Período de armazenamento (ano da colheita) & Germinação(\%) & Índice de velocidade de germinação* \\
\hline Um ano (2002) & $41 \mathrm{a}$ & $7,6 \mathrm{~b}$ \\
Dois anos (2001) & $51 \mathrm{a}$ & 10,3 a \\
Três anos (2000) & $23 \mathrm{~b}$ & $4,7 \mathrm{c}$ \\
Quatro anos (1999) & $30 \mathrm{~b}$ & $5,2 \mathrm{c}$ \\
CV(\%) & 10,44 & 20,15 \\
\hline
\end{tabular}

Médias não seguidas de mesma letra na coluna diferem entre si pelo teste de Tukey a $5 \%$ de probabilidade de erro.

"O índice de velocidade de germinação (IVG) é dado pela fórmula IVG $=\mathrm{G}_{1} / \mathrm{N}_{1}+\mathrm{G}_{2} / \mathrm{N}_{2}+\ldots+\mathrm{Gn} / \mathrm{Nn}$; onde $\mathrm{G}_{1}, \mathrm{G}_{2}$, Gn $=$ número de plântulas computadas na primeira, na segunda e na última contagem; e $\mathrm{N}_{1}, \mathrm{~N}_{2}, \mathrm{Nn}=$ número de dias de semeadura à primeira, segunda e última contagens.

do período de armazenamento (Tabela 1). O mesmo aconteceu com sementes de pau-pereira (Platycyamus regnelli Benth), que tiveram sua velocidade de germinação diminuída com os meses de armazenamento (SCALON et al., 1993).

Sementes armazenadas durante um ano apresentaram índice de velocidade de germinação menor do que as sementes armazenadas por dois anos. Provavelmente, isto ocorreu devido à dormência das sementes de camomila que, segundo BRASIL (1992), é superada por pré-resfriamento de $5^{\circ} \mathrm{C}$ a $10^{\circ} \mathrm{C}$ durante sete dias, ou devido às melhores condições climáticas durante a formação das sementes (TOLEDO \& MARCOS FILHO, 1977).

Segundo experimento

Todas as temperaturas testadas, constantes e alternadas, foram eficientes para promover germinação das sementes de camomila ao final (total) do 14ํㅡ. DAS. Verificou-se grande diferença no número de plântulas formadas ao sétimo dia, indicando que algumas temperaturas aceleram a germinação das sementes de camomila. $\mathrm{O}$ uso de temperatura constante de $10^{\circ} \mathrm{C}$ apresentou apenas 3\% de sementes germinadas ao sétimo DAS, enquanto que o emprego de temperaturas constantes de $15^{\circ} \mathrm{C}$ e alternadas de $10-15^{\circ} \mathrm{C}$ e $10-20^{\circ} \mathrm{C}$ promoveram germinação de 70 a $80 \%$ já na primeira contagem (Tabela 2). A temperatura da água de embebição na qual a semente está germinando exerce efeito considerável sobre o processo. Temperaturas abaixo da ótima tendem a reduzir a velocidade do processo de germinação (CARVALHO \& NAKAGAWA, 2000). BURCH \& DELOUCHE (1959), trabalhando com quatro espécies, verificaram que, na temperatura de $30^{\circ} \mathrm{C}$, os teores de água (\%) absorvidos são maiores que a $20^{\circ} \mathrm{C}$.

Houve interação entre as temperaturas utilizadas e as épocas de contagem. As sementes de camomila atingiram o pico de germinação no $14^{\circ} \mathrm{DAS}$ com o uso da temperatura constante de $10^{\circ} \mathrm{C}$ e ao $7^{\circ}$ DAS com a temperatura constante de $15^{\circ} \mathrm{C}$, e alternadas de $10-15^{\circ} \mathrm{C}$ e de $10-20^{\circ} \mathrm{C}$ (Tabela 2).

Os resultados do experimento demonstraram que as temperaturas de $10^{\circ} \mathrm{C}, 10-15^{\circ} \mathrm{C} \mathrm{e}$ $10-20^{\circ} \mathrm{C}$ promoveram alta germinação na segunda contagem, tal como o uso de temperatura constante de $15^{\circ} \mathrm{C}$ sugerida por NÓBREGA et al. (1995). O experimento mostrou também que a temperatura utilizada não precisa ser constante, como sugere os resultados de AGUILERA(1998).

Tabela 2 - Porcentagem de germinação da semente de camomila submetida a quatro tratamentos de temperaturas, ao sétimo e ao décimo quarto dia após a semeadura (DAS), e o número total de sementes germinadas. Londrina, PR. 2004.

\begin{tabular}{lccc}
\hline Tratamentos & Germinação ao $7^{\circ}$ DAS (\%) & Germinação ao 14 ${ }^{\circ}$ DAS (\%) & Germinação total (\%) \\
\hline $10^{\circ} \mathrm{C}$ & $3 \mathrm{~b} \mathrm{~B}$ & 79 a A & 82 a \\
$15^{\circ} \mathrm{C}$ & $82 \mathrm{a} \mathrm{A}$ & $6 \mathrm{c} \mathrm{B}$ & 88 a \\
$10-15^{\circ} \mathrm{C}$ & $70 \mathrm{a} \mathrm{A}$ & $15 \mathrm{~b} \mathrm{~B}$ & 86 a \\
$10-20^{\circ} \mathrm{C}$ & $80 \mathrm{a} \mathrm{A}$ & $7 \mathrm{c} \mathrm{B}$ & $88 \mathrm{a}$ \\
$\mathrm{CV} \%$ & 5,68 & 11,72 & 2,24 \\
\hline
\end{tabular}

Médias não seguidas de mesmas letras, minúsculas na coluna e maiúsculas na linha, diferem significativamente pelo Teste de Tukey a 5\% de probabilidade de erro.

Ciência Rural, v.37, n.4, jul-ago, 2007. 


\section{CONCLUSÕES}

O armazenamento pelo período de dois anos não afetou o potencial de germinação e o índice de velocidade de germinação das sementes de camomila. A germinação das sementes reduziu-se para 3,3\% com a temperatura de $10^{\circ} \mathrm{C}$ ao sétimo dia após a semeadura. A aplicação de temperaturas constantes de $10^{\circ} \mathrm{C}$ e $15^{\circ} \mathrm{C}$ e de alternadas de $10-15^{\circ} \mathrm{C}$ e $10-20^{\circ} \mathrm{C}$ proporcionaram germinação das sementes superior a $80 \%$ ao final do décimo quarto dia após a semeadura.

\section{REFERÊNCIAS}

AGRO-FAUNA. Floricultura: Paraná vai colher 30\% menos camomila na safra 2003. Capturado em 04 out. 2004. Online. Disponível em: <http://www.agro-fauna.com.br/noticias. php?nid=4701>. Fonte: Gazeta do Povo.

AGUILERA, D.B. Efeitos de temperaturas e substratos na germinação de sementes de camomila (Matricaria chamomila). 1998. 13f. Monografia (Trabalho de conclusão de curso) - Curso de Graduação em Agronomia, Universidade Estadual de Londrina.

ARAÚJO, E.F. et al. Avaliação da qualidade de sementes de açaí armazenadas em diferentes embalagens e ambientes. Revista Brasileira de Sementes, v.16, n.1, p.76-79, 1994.

BRASIL. Ministério da Agricultura e reforma Agrária. Regras para análises de sementes. Brasília: SNDA/DNDV/CLAV, 1992. 355p.

BURCH, A.; DELOUCHE, J.C. Absorption of water by seeds. Proceedings of the Association Official Seeds Analysts. v.49, p.142-150, 1959.

CARVALHO, N.M.; NAKAGAWA, J. Sementes: ciência, tecnologia e produção. 4.ed. Jaboticabal: FUNEP, 2000. 588p.

CORREA JÚNIOR, C.; TANIGUCHI, E. Aspectos da cultura de camomila no estado do Paraná. In: CONGRESSO BRASILEIRO DE OLERICUlTURA, 32., 1992, Aracajú. Resumos... Brasília: Associação Brasileira de Olericultura, 1992. p.8.

DELOUCHE, J.C. et al. Storage of seed in sub-tropical and tropical regions. Seed Science and Technology, v.1, n.3, p.671-700. 1973.

GROB, B. Viability of seed of Brachiaria decumbens. In: Germinação e viabilidade de sementes de Brachiaria decumbens (Hochst. Ex. A.Rich.) Staf durante o armazenamento. Revista Brasileira de Sementes, v.18, n.2, p.262-266, 1968.
KRZYZANOWSKI, F.C. et al. Vigor de sementes: conceitos e testes. Londrina: ABRATES, Comitê de Vigor de Sementes, 1999. 218p.

LORENZI, H.; MATOS, F.J. de. Plantas medicinais no Brasil: nativas e exóticas cultivadas. Nova Odessa: Instituto Plantarum 2002. 512p.

NÓBREGA, L.H.P. et al. Efeito da luz e da temperatura na germinação de sementes de camomila (Matricaria recutita). Revista Brasileira de Sementes, v.17, n.2, p.137-140, 1995.

PIÑA-RODRIGUEZ, F.C.M.; JESUS, R.M. Comportamento das sementes de cedro-rosa (Cedrella angustifolia S. ET. MOC.) durante o armazenamento. Revista Brasileira de Sementes, v.14, n.1, p.31-36, 1992.

PIZZINATTO, M.A. et al. Relação entre densidade e qualidade de sementes de algodoeiro. Bragantia, v.50, n.2, p.269-289. 1991.

POPINIGIS, F. Fisiologia da semente. 2.ed. Brasília: AGIPLAN, 1985. 289p.

SCALON, S.P.Q. et al. Influência do substrato, temperatura, umidade e armazenamento sobre a germinação de sementes de pau pereira (Platycyamus regnelli Benth). Revista Brasileira de Sementes, v.15, n.1, p.143-146, 1993.

SOUZA, J.R.P. de. et al. Método para beneficiamento de sementes de camomila (Matricaria chamomilla L.). Revista Brasileira de Sementes, v.2, n.1, p.38-41, 2000.

STUMPF, M. et al. Determination of natural estrogens in sewage treatment plants and river water. Vom Wasser, v.87, p.251-261, 1996.

TAKAHASHI, L.S.A. et al. Germinação de sementes de camomila (Matricaria chamomilla L.) em diferentes substratos e temperaturas. Horticultura Brasileira, v.19, n.2, p.232, 2001.

TOLEDO, F.F.; MARCOS FILHO, J. Manual de sementes: Tecnologia da produção. São Paulo: Agronômica Ceres, 1977. p.185-187.

TOMPSETT, P.B. A review of the literature on storage of dipterocarp seeds. Seed Science and Technology, v.20, n.2, p.251-267, 1992.

ZAIDAN, L.B.P.; BARBEDO, C.J. Quebra de dormência em sementes. In: FERREIRA, A.G.; BORGHETTI, F. (Orgs.) Germinação - do básico ao aplicado. Porto Alegre: Artmed, 2004. Cap. 8, p.135-146. 